\title{
Biodistribution and PET Imaging of Labeled Bispecific T Cell-Engaging Antibody Targeting EpCAM
}

\author{
Frank J. Warnders ${ }^{1}$, Stijn J.H. Waaijer*2, Martin Pool*2, Marjolijn N. Lub-de Hooge ${ }^{1,3}$, Matthias Friedrich ${ }^{4}$, \\ Anton G.T. Terwisscha van Scheltinga ${ }^{1}$, Petra Deegen ${ }^{4}$, Sabine K. Stienen ${ }^{4}$, Peter C. Pieslor ${ }^{5}$, H. Kam Cheung ${ }^{5}$, \\ Jos G.W. Kosterink ${ }^{1,6}$, and Elisabeth G.E. de Vries ${ }^{2}$ \\ ${ }^{I}$ Department of Clinical Pharmacy and Pharmacology, University of Groningen, University Medical Center Groningen, Groningen, \\ The Netherlands; ${ }^{2}$ Department of Medical Oncology, University of Groningen, University Medical Center Groningen, Groningen, The \\ Netherlands; ${ }^{3}$ Department of Nuclear Medicine and Molecular Imaging, University of Groningen, University Medical Center \\ Groningen, Groningen, The Netherlands; ${ }^{4}$ Amgen Research (Munich) GmbH, Munich, Germany; ${ }^{5}$ Amgen, Thousand Oaks, \\ California; and ${ }^{6}$ Department of Pharmacy, Section of Pharmacotherapy and Pharmaceutical Care, University of Groningen, \\ Groningen, The Netherlands
}

AMG 110, a bispecific T cell engager (BiTE) antibody construct, induces $T$ cell-mediated cancer cell death by cross-linking epithelial cell adhesion molecule (EpCAM) on tumor cells with a cluster of differentiation $3 \varepsilon(C D 3 \varepsilon)$ on T cells. We labeled AMG 110 with ${ }^{89} \mathrm{Zr}$ or nearinfrared fluorescent dye (IRDye) $800 \mathrm{CW}$ to study its tumor targeting and tissue distribution. Methods: Biodistribution and tumor uptake of ${ }^{89} \mathrm{Zr}$-AMG 110 was studied up to $6 \mathrm{~d}$ after intravenous administration to nude BALB/c mice bearing high EpCAM-expressing HT-29 colorectal cancer xenografts. Tumor uptake of ${ }^{89} \mathrm{Zr}$-AMG 110 was compared with uptake in head and neck squamous cell cancer FaDu (intermediate EpCAM) and promyelocytic leukemia HL60 (EpCAM-negative) xenografts. Intratumoral distribution in HT-29 tumors was studied using 800CW-AMG 110. Results: Tumor uptake of ${ }^{89} \mathrm{Zr}$-AMG 110 can be clearly visualized using small-animal PET imaging up to $72 \mathrm{~h}$ after injection. The highest tumor uptake of ${ }^{89} \mathrm{Zr}-\mathrm{AMG} 110$ at the $40-\mu \mathrm{g}$ dose level was observed at 6 and $24 \mathrm{~h}$ (respectively, $5.35 \pm 0.22$ and $5.30 \pm$ 0.20 percentage injected dose per gram; $n=3$ and 4). Tumor uptake of 89Zr-AMG 110 was EpCAM-specific and correlated with EpCAM expression. $800 \mathrm{CW}$-AMG 110 accumulated at the tumor cell surface in viable EpCAM-expressing tumor tissue. Conclusion: PET and fluorescent imaging provided real-time information about AMG 110 distribution and tumor uptake in vivo. Our data support using ${ }^{89} \mathrm{Zr}$ and IRDye $800 \mathrm{CW}$ to evaluate tumor and tissue uptake kinetics of bispecific T cell engager antibody constructs in preclinical and clinical settings.

Key Words: imaging; PET; fluorescence; BiTE; ${ }^{89} \mathrm{Zr}$

J Nucl Med 2016; 57:812-817

DOI: 10.2967/jnumed.115.168153

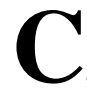

ancer remains a major cause of death worldwide and one of the key disease areas with the greatest unmet medical needs. Therefore, new treatment strategies are eagerly awaited. The use

Received Nov. 3, 2015; revision accepted Jan. 13, 2016.

For correspondence or reprints contact: Elisabeth G.E. de Vries, Department of Medical Oncology, University of Groningen, University Medical Center Groningen, P.O. Box 30.001, 9700 RB Groningen, The Netherlands.

E-mail: e.g.e.de.vries@umcg.nl

${ }^{*}$ Contributed equally to this work.

Published online Feb. 4, 2016.

COPYRIGHT (C 2016 by the Society of Nuclear Medicine and Molecular Imaging, Inc. of $\mathrm{T}$ cells, especially cytotoxic $\mathrm{T}$ cells, in the battle against cancer has shown promising results using several approaches (1). However, most of these strategies are sensitive to inhibitory or escape mechanisms, such as major histocompatibility complex class I downregulation or induction of $\mathrm{T}$ cell tolerance, which can limit antitumor efficacy $(2,3)$.

Bispecific T cell engager (BiTE) antibody constructs are created to circumvent such inhibitory or escape mechanisms. They comprise 2 single-chain variable antibody fragments $(\mathrm{scFv})$ that are covalently linked by a peptide linker and bind cluster of differentiation $3 \varepsilon$ $(\mathrm{CD} 3 \varepsilon)$ as well as a surface target antigen on cancer cells (4). The activation of $\mathrm{T}$ cells by BiTE antibody constructs is independent of matching major histocompatibility complex class I or costimulatory molecules $(5,6)$. Furthermore, BiTE antibody constructs engage a polyclonal population of $\mathrm{T}$ cells, including $\mathrm{CD} 4^{+}$and mainly $\mathrm{CD}{ }^{+}$ T cells (7). Binding of tumor cells and T cells by BiTE antibody constructs results in the formation of a cytolytic synapse between tumor and $\mathrm{T}$ cells, which is followed by a release of pore-forming and pro-apoptotic components of cytotoxic $\mathrm{T}$ cell granules, mediating cancer cell death $(5,7)$. The activation of $\mathrm{T}$ cells occurs only in the presence of a target cell (8). To date, 4 BiTE antibody constructs, blinatumomab, BAY2010112/AMG 212, MT111/AMG 211, and MT110/AMG 110, are or have been tested in clinical trials. Blinatumomab has been approved by the U.S. Food and Drug Administration to treat patients with Philadelphia chromosome-negative precursor B-cell acute lymphoblastic leukemia.

Epithelial cell adhesion molecule (EpCAM) is expressed on many epithelial tumors and cancer stem cells (9) and is therefore an attractive target for BiTE antibody constructs. An EpCAMtargeting BiTE called solitomab (AMG 110, formerly known as MT110) has been developed (10). AMG 110 mediates lysis of cancer cells by the activation of $\mathrm{T}$ cells in vitro and showed pharmacologic activity at doses administered of at least $24 \mu \mathrm{g} / \mathrm{d}$ in the clinic (11).

To support clinical development of AMG 110 and other BiTE antibody constructs, molecular imaging can be used as a powerful noninvasive tool to obtain valuable information on tumor uptake, biodistribution, and pharmacokinetics. In a clinical setting, this information can potentially be used to support patient-tailored drug dosing. Because of its long radioactivity decay half-life of $3.27 \mathrm{~d}$, ${ }^{89} \mathrm{Zr}$ is well suited for capturing the in vivo pharmacokinetics of large molecules, such as antibodies (12). In addition, labeling 
antibodies with the near-infrared (NIR) fluorescent dye $800 \mathrm{CW}$ can be used to study their intratumoral tumor distribution with NIR fluorescence imaging and to enable molecular characterization of tumor and tissue sections ex vivo (13). We therefore labeled AMG 110 with ${ }^{89} \mathrm{Zr}$ or IRDye $800 \mathrm{CW}$ to study its tumor targeting and tissue distribution via noninvasive small-animal PET and fluorescence imaging.

\section{MATERIALS AND METHODS}

\section{BiTE Antibody Constructs and Cell Lines}

AMG 110 is a BiTE antibody construct targeting human EpCAM and human CD3e. The nonspecific control BiTE Mec14 shares the same anti-CD3 $\varepsilon$ single-chain antibody arm but targets a haptene (mecoprop) with the second arm. Both BiTE antibody constructs, $55 \mathrm{kDa}$ or more in size, were provided by Amgen. Two human EpCAM-positive tumor cell lines, the colorectal adenocarcinoma HT-29 cell line and the head and neck squamous cell cancer FaDu cell line, and a human EpCAM-negative promyelocytic leukemia HL-60 cell line were used. We used HT-29 xenografts to study doseand time-dependent tumor uptake of ${ }^{89} \mathrm{Zr}$-AMG110 because this cell line highly expresses EpCAM (14). We additionally used this cell line to compare EpCAM-dependent tumor uptake of ${ }^{89} \mathrm{Zr}$-AMG110 with ${ }^{89} \mathrm{Zr}$-Mec14. All cell lines were obtained from American Type Culture Collection and screened for microbial contamination and tested negative. Cell lines were authenticated by Baseclear using short tandem repeat profiling. This was repeated once a cell line had been passaged for more than 6 mo after previous short tandem repeat profiling. HT-29 and HL-60 were routinely cultured in RPMI1640 medium (Invitrogen) containing 10\% fetal calf serum (Bodinco $\mathrm{BV}) . \mathrm{FaDu}$ cells were cultured in Dulbecco modified Eagle medium (Invitrogen) supplemented with $10 \%$ fetal calf serum and $2 \mathrm{mM}$ L-glutamine (Invitrogen). All cells were cultured under humidified conditions $\left(37^{\circ} \mathrm{C}, 5 \% \mathrm{CO}_{2}\right)$.

\section{Animal Experiments}

All animal experiments were approved by the Institutional Animal Care and Use Committee of the University of Groningen and conducted in male nude BALB/c mice (BALB/cOlaHsd-Foxn1nu; Harlan). After 1 wk of acclimatization, 6- to 8-wk-old mice were subcutaneously injected with $10 \times 10^{6}$ HT-29 cells in $0.1 \mathrm{~mL}$ of phosphate-buffered saline, with $5 \times 10^{6} \mathrm{FaDu}$ cells in $0.1 \mathrm{~mL}$ of phosphate-buffered saline, or with $2 \times 10^{6} \mathrm{HL}-60$ cells in $0.1 \mathrm{~mL}$ of phosphate-buffered saline. Tumor growth was monitored by caliper measurements. Penile vein tracer injection was performed $3 \mathrm{wk}$ after inoculation of HT-29 cells, 4 wk after inoculation of $\mathrm{FaDu}$ cells, and $5 \mathrm{wk}$ after inoculation for HL-60 cells. All scans and invasive proceedings were performed with isoflurane/medical air inhalation anesthesia (5\% induction, $2.5 \%$ maintenance) for a maximum of $90 \mathrm{~min}$.

\section{PET Acquisition}

Two mice were placed above each other in a Focus 220 rodent scanner (CTI Siemens), with the tumor in the field of view. Mice were kept warm on heating mats. Acquisition times differed between $10 \mathrm{~min}$ (0.5-h time point) and $75 \mathrm{~min}$ (144-h time point). A transmission scan of $515 \mathrm{~s}$ was obtained using a ${ }^{57} \mathrm{Co}$ point source to correct for tissue attenuation.

\section{In Vivo PET Imaging and Ex Vivo Biodistribution}

For determining the time point for optimal tumor visualization, small-animal PET images were obtained 0.5, 3, 6, 24, 48, and $72 \mathrm{~h}$ after injection of $20 \mu \mathrm{g}$ of ${ }^{89} \mathrm{Zr}$-AMG 110 (5 MBq). Data up to $24 \mathrm{~h}$ were obtained from 6 mice, and data at 48 and $72 \mathrm{~h}$ were obtained from 2 mice.
For ex vivo biodistribution, animals were sacrificed at designated time points. Subsequently, organs and tissues were excised and weighed. Samples and prime standards were counted for radioactivity in a calibrated well-type $\gamma$-counter. Ex vivo tissue activity was expressed as percentage injected dose per gram of tissue (\% ID/g).

A dose escalation biodistribution study was performed with 20 ( $n=$ 5), $40(n=4)$, and $500 \mu \mathrm{g}(n=3)$ of ${ }^{89} \mathrm{Zr}-\mathrm{AMG} 110(1 \mathrm{MBq})$ at $24 \mathrm{~h}$ after injection. Tumor weights did not differ significantly between the dose groups $(0.23 \pm 0.09,0.33 \pm 0.27$, and $0.47 \pm 0.62 \mathrm{~g}$, respectively $)$ (Supplemental Fig. 1A; supplemental materials are available at http:// jnm.snmjournals.org). Doses higher than $20 \mu \mathrm{g}$ were supplemented with nonradiolabeled AMG 110 . For the $40-\mu \mathrm{g}$ protein dose, ${ }^{89} \mathrm{Zr}-\mathrm{AMG} 110$ (1 MBq) time-dependent tumor uptake was also determined. Biodistribution studies were performed at $6(n=3), 24(n=4), 72(n=4)$, and $144(n=5) \mathrm{h}$ after tracer injection. Tumor weights did not differ significantly between different groups $(0.20 \pm 0.01,0.33 \pm 0.27,0.33 \pm$ 0.10 , and $0.35 \pm 0.15 \mathrm{~g}$, respectively) (Supplemental Fig. 1B).

To determine nonspecific tumor uptake, $40 \mu \mathrm{g}(1 \mathrm{MBq})$ of ${ }^{89} \mathrm{Zr}-\mathrm{Mec} 14$ $(n=6)$ or ${ }^{89} \mathrm{Zr}$-AMG $110(n=4)$ were administered intravenously to mice harboring HT-29 tumors. Tumor weights did not differ significantly between the 2 groups $(0.32 \pm 0.11$ and $0.33 \pm 0.27 \mathrm{~g}$, respectively) (Supplemental Fig. 1C). Small-animal PET scans and ex vivo biodistribution were performed $24 \mathrm{~h}$ after tracer injection, at the time when tumor uptake of ${ }^{89} \mathrm{Zr}$-AMG 110 would be high and blood levels relatively low. The biologic half-life of ${ }^{89} \mathrm{Zr}$-AMG 110 in whole blood and tumor was calculated using either \%ID per cubic centimeter $\left(\% \mathrm{ID} / \mathrm{cm}^{3}\right)(20-\mu \mathrm{g}$ tracer dose, as used for determining optimal time point) based on smallanimal PET scans or \% ID/g (40- $\mu \mathrm{g}$ protein dose) by nonlinear regression (1-phase exponential decay) using GraphPad Prism (GraphPad Software).

EpCAM-specific uptake in relation to EpCAM expression was assessed with small-animal PET imaging $24 \mathrm{~h}$ after injection of $40 \mu \mathrm{g}$ of ${ }^{89} \mathrm{Zr}$-AMG 110 in xenografted mice ( $n=4-6$ per group) bearing HT-29, FaDu, or HL-60 tumors. Thereafter, mice were sacrificed for ex vivo biodistribution analysis. Tumor weights did not differ significantly between the tumor models $(0.33 \pm 0.27,0.20 \pm 0.13$, and $0.34 \pm 0.10 \mathrm{~g}$, respectively) (Supplemental Fig. 1D).

\section{PET Reconstruction}

PET data were reconstructed using a 2-dimensional ordered-subset expectation maximization reconstruction algorithm with Fourier rebinning, 4 iterations, and 16 subsets. After reconstruction, images were quantified using AMIDE Medical Image Data Examiner software (version 1.0.4; Stanford University). Regions of interest were drawn for tumor and blood (heart). The level of ${ }^{89} \mathrm{Zr}-\mathrm{AMG} 110$ or ${ }^{89} \mathrm{Zr}-\mathrm{Mec} 14$ was calculated as $\% \mathrm{ID} / \mathrm{cm}^{3}$.

\section{Ex Vivo Fluorescent Imaging}

For NIR fluorescence imaging, mice bearing HT-29 xenografts $(n=4)$ were coinjected with $40 \mu \mathrm{g}$ of $800 \mathrm{CW}-\mathrm{AMG} 110$ and $40 \mu \mathrm{g}$ of 680RD-Mec14. At $24 \mathrm{~h}$ after injection mice, were sacrificed and tumor tissue was excised, formalin-fixed, and paraffin-embedded. Tumor slices were stained immunohistochemically for EpCAM (D9S3P; Cell Signaling) and with hematoxylin and eosin. Overview images of intratumoral 680RD-Mec14 and 800CW-AMG 110 distribution were obtained with the Odyssey infrared imaging system (LI-COR Biosciences). For fluorescence microscopy, an inverted Leica DMI600B fluorescence microscope equipped with a Lumen Dynamics X-Cite 200DC light source was used. Nuclei were stained with 4',6-diamidino-2phenylindole (DAPI; Sigma-Aldrich).

\section{Statistical Analysis}

Data are presented as mean \pm SD. Statistical analysis between 2 groups was performed using the Mann-Whitney $U$ test (GraphPad Prism 5). To test whether differences between multiple groups were 
significant, we used a Kruskal-Wallis test (GraphPad Prism 5). A Bonferroni-corrected Mann-Whitney $U$ test was subsequently used to compare differences between 2 groups. $P$ values of 0.05 or less were considered significant.

\section{RESULTS}

In Vivo Evaluation of ${ }^{89} \mathrm{Zr}$-AMG 110 and $800 \mathrm{CW}$-AMG 110

Small-animal PET images of the $20-\mu \mathrm{g}{ }^{89} \mathrm{Zr}$-AMG 110 dose showed time-dependent tumor accumulation, with a maximum of $3.25 \pm 0.24 \% \mathrm{ID} / \mathrm{cm}^{3}$ at $6 \mathrm{~h}$ after injection (Figs. $1 \mathrm{~A}$ and 1B) and decreasing subsequently. Following the same pattern, kidneys showed the highest tissue uptake across time points, reaching a maximum of $60.26 \pm 4.01 \% \mathrm{ID} / \mathrm{cm}^{3}$ at $6 \mathrm{~h}$, indicating renal clearance. Blood levels of ${ }^{89} \mathrm{Zr}$-AMG 110 dropped rapidly (biologic half-life, $1.51 \mathrm{~h}$; Supplemental Fig. 4A). The washout of the tumor was relatively slow (biologic half-life, 99.9 h; Supplemental Fig. 4B), starting at $6 \mathrm{~h}$ after injection. This resulted in increasing tumor-to-blood ratios over time, reaching $1.13 \pm 0.29$, $3.67 \pm 0.29,4.10 \pm 0.42$, and $3.53 \pm 1.03$, respectively, at 6,24 , 48 , and $72 \mathrm{~h}$.

A $40-$ and $500-\mu \mathrm{g}$ protein dose resulted in a higher (not statistically significant) and more reproducible tumor uptake of ${ }^{89} \mathrm{Zr}-\mathrm{AMG}$ 110 than $20 \mu \mathrm{g}(5.30 \pm 0.21$ and $4.9 \pm 0.21$ vs. $3.6 \pm 1.2 \% \mathrm{ID} / \mathrm{g}$; $P=0.57$ and 0.75 , respectively, Fig. 2A). No statistically significant differences were found in tumor-to-blood or tumor-to-muscle ratios among the different protein doses tested (Supplemental Figs. 5A and 5B). All organs showed similar ${ }^{89} \mathrm{Zr}$-AMG 110 levels at all protein doses. Highest ${ }^{89} \mathrm{Zr}$-AMG 110 levels were found in the kidneys, followed by liver and tumor. Because of a more reproducible tumor uptake, the remainder of the study was performed with a 40- instead of a $20-\mu \mathrm{g}$ dose level.

The duration and level of ${ }^{89} \mathrm{Zr}$-AMG 110 tumor exposure was protein-dose-dependent and differed from blood. Biodistribution of $40 \mu \mathrm{g}$ of ${ }^{89} \mathrm{Zr}$-AMG 110 in time resulted in a maximum tumor uptake at 6 and $24 \mathrm{~h}$ after injection of $5.4 \pm 0.2$ and $5.3 \pm 0.3$

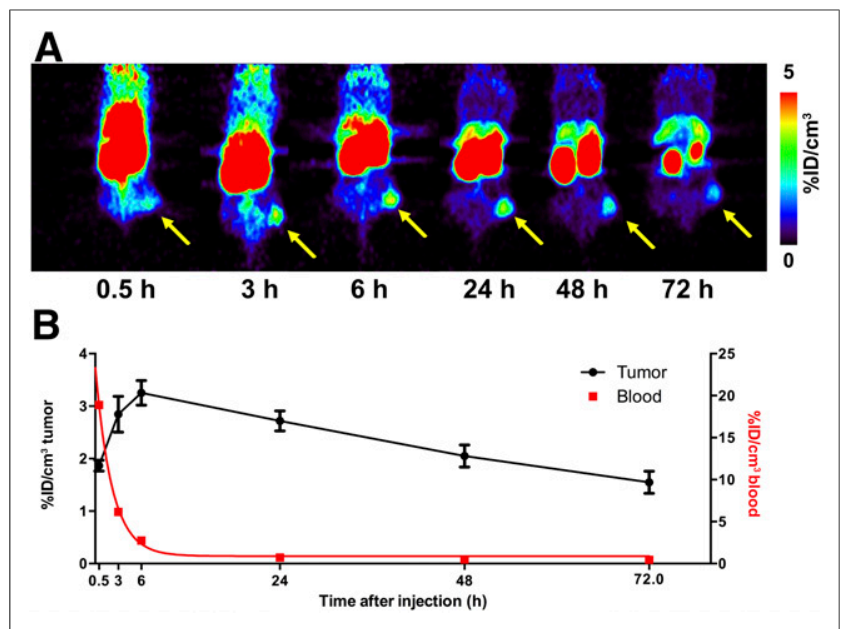

FIGURE 1. Biodistribution of $89 \mathrm{Zr}-\mathrm{AMG} 110$ at $20-\mu \mathrm{g}$ dose level. (A) Representative serial small-animal PET imaging at $0.5,3,6,24,48$, and $72 \mathrm{~h}$ after injection in $1 \mathrm{HT}-29-$ bearing mouse. Yellow arrows indicate tumor. (B) In vivo quantification of tumor and blood levels of ${ }^{89} \mathrm{Zr}-\mathrm{AMG}$ 110 in time as presented in $\% \mathrm{ID} / \mathrm{cm}^{3}$. Data up to $24 \mathrm{~h}$ were obtained from 6 mice, and data at 48 and $72 \mathrm{~h}$ were obtained from 2 mice. Data are mean $\pm \mathrm{SD}$.
$\%$ ID/g, respectively (Fig. 3A), declining subsequently. In contrast, tumor uptake after injection of $20 \mu \mathrm{g}$ of ${ }^{89} \mathrm{Zr}$-AMG 110 already peaked at $6 \mathrm{~h}$ and declined steadily thereafter (Fig. 1B). The biologic half-life of ${ }^{89} \mathrm{Zr}$-AMG 110 after injection of a protein dose of $40 \mu \mathrm{g}$ in blood was $4.1 \mathrm{~h}$ compared with $1.5 \mathrm{~h}$ for the $20-\mu \mathrm{g}$ protein dose (Supplemental Fig. 4C). Washout of signal from the tumor was relatively slow compared with blood (half-life, $40.2 \mathrm{~h}$; Supplemental Fig. 4D). The prolonged tumor retention of $40 \mu \mathrm{g}$ of ${ }^{89} \mathrm{Zr}$-AMG 110 resulted in increasing tumor-to-blood ratios over time, reaching $65.1 \pm 15.5$ at $144 \mathrm{~h}$ (Fig. 3B). The maximal tumor-to-muscle ratio was reached at $24 \mathrm{~h}(18.6 \pm 3.6)$.

HT-29 xenografts specifically retained ${ }^{89} \mathrm{Zr}$-AMG 110 but not the non-EpCAM binding ${ }^{89} \mathrm{Zr}-\mathrm{Mec} 14 \mathrm{BiTE}$. Biodistribution of ${ }^{89} \mathrm{Zr}-\mathrm{Mec} 14$ showed low tumor uptake of $0.7 \pm 0.1 \% \mathrm{ID} / \mathrm{g}$ compared with $5.3 \pm 0.3 \% \mathrm{ID} / \mathrm{g}$ for ${ }^{89} \mathrm{Zr}-\mathrm{AMG} 110$ at $24 \mathrm{~h}$ (Fig. $4 \mathrm{~A}$; $P<0.01)$. Accumulation of ${ }^{89} \mathrm{Zr}-\mathrm{Mec} 14$ in blood and all organs except the kidneys was lower $(\leq 2.4 \% \mathrm{ID} / \mathrm{g})$ than ${ }^{89} \mathrm{Zr}$-AMG 110 $(\leq 5.6 \% \mathrm{ID} / \mathrm{g}) .{ }^{89} \mathrm{Zr}-\mathrm{Mec} 14$ tumor uptake was comparable to nonspecific uptake in other organs. As a result, a higher tumor-to-blood (33.4 \pm 3.1 vs. $7.3 \pm 1.2 ; P<0.01$; Fig. $4 \mathrm{~B})$ and a higher tumorto-muscle ratio $(18.6 \pm 3.6$ vs. $6.7 \pm 0.8 ; P<0.01)$ were observed for ${ }^{89} \mathrm{Zr}$-AMG 110 . In line with these results, small-animal PET images showed lower tumor uptake of ${ }^{89} \mathrm{Zr}-\mathrm{Mec} 14$ than ${ }^{89} \mathrm{Zr}-\mathrm{AMG}$ 110 (Fig. 4C).

Tumor uptake of ${ }^{89} \mathrm{Zr}$-AMG 110 was correlated with the level of cell surface EpCAM expression (Fig. 5). It was highest in HT29 tumors $(5.3 \pm 0.3 \% \mathrm{ID} / \mathrm{g})$ followed by $\mathrm{FaDu}(2.7 \pm 0.6 \% \mathrm{ID} / \mathrm{g})$ and HL-60 $(0.8 \pm 0.2 \% \mathrm{ID} / \mathrm{g})$, whereas no differences were observed in uptake of normal organs in mice bearing the different tumor xenografts (Fig. 5A). Difference in tumor uptake could be clearly visualized by small-animal PET (Fig. 5B).

In vivo and ex vivo fluorescence imaging confirmed AMG 110-specific cell surface binding of HT-29 xenografts. Similar to ${ }^{89} \mathrm{Zr}$-AMG 110 , in vivo imaging showed HT-29 retention of 800CW-AMG 110 but not 680RD-Mec14 (Supplemental Fig. 6A). In accordance with low tumor levels found for ${ }^{89} \mathrm{Zr}-\mathrm{Mec} 14$ at biodistribution $24 \mathrm{~h}$ after tracer injection, 680RD-Mec14 was cleared rapidly, with a level detectable only ex vivo by $24 \mathrm{~h}$ (Supplemental Fig. 6B). Ex vivo macroscopic fluorescence imaging of HT-29 tumor slices showed 800CW-AMG 110 colocalizing with viable EpCAM-expressing tumor tissue, as shown by hematoxylin and eosin and EpCAM staining (Figs. 6A and 6B). Fluorescence

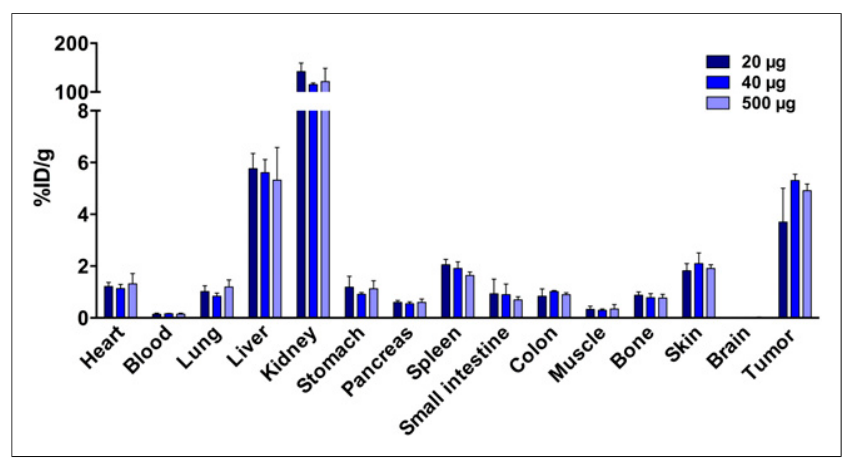

FIGURE 2. Dose-dependent ${ }^{89} \mathrm{Zr}$-AMG 110 biodistribution in HT-29tumor bearing mice at $24 \mathrm{~h}$ after tracer injection. Mice were injected with 20- $(n=5), 40-(n=4)$, or 500- $\mu \mathrm{g}(n=3)$ protein doses. No significant differences were observed in organ and tumor uptake between dose groups. Data are mean \pm SD. 


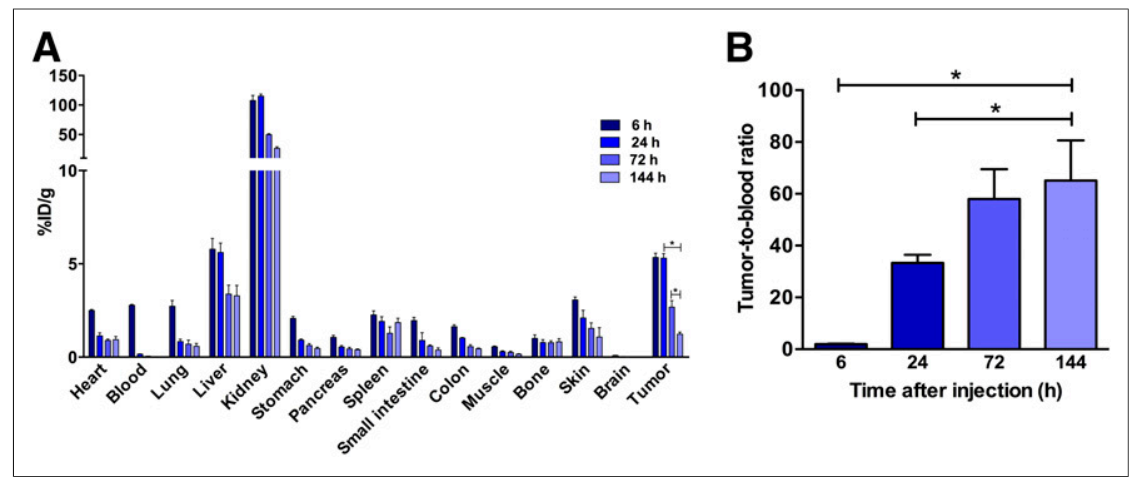

FIGURE 3. Time-dependent ${ }^{89} \mathrm{Zr}$-AMG $110(40 \mu \mathrm{g})$ biodistribution in HT-29-bearing mice. (A) Ex vivo biodistribution of ${ }^{89} \mathrm{Zr}$-AMG 110 was performed at $6(n=3), 24(n=4), 72(n=4)$, and $144 \mathrm{~h}$ $(n=5)$ after injection. (B) Corresponding tumor-to-blood ratios increased significantly. Data are mean \pm SD. Significance has been calculated for differences in tumor uptake and tumor-to-blood ratios. ${ }^{*} P \leq 0.05$.

microscopy also showed presence of $800 \mathrm{CW}-\mathrm{AMG} 110$ on the tumor cell surface (Fig. 6C). In contrast, non-EpCAM binding 680RD-Mec14 mostly localized in necrotic tumor tissue.

\section{DISCUSSION}

We present the first, to our knowledge, noninvasive preclinical imaging study in which a bispecific $\mathrm{T}$ cell-engaging antibody construct targeting EpCAM is labeled with a radionuclide, or a fluorophore, to visualize and quantify tumor uptake, tissue accumulation, and clearance kinetics in vivo. In this study, ${ }^{89} \mathrm{Zr}-\mathrm{AMG}$

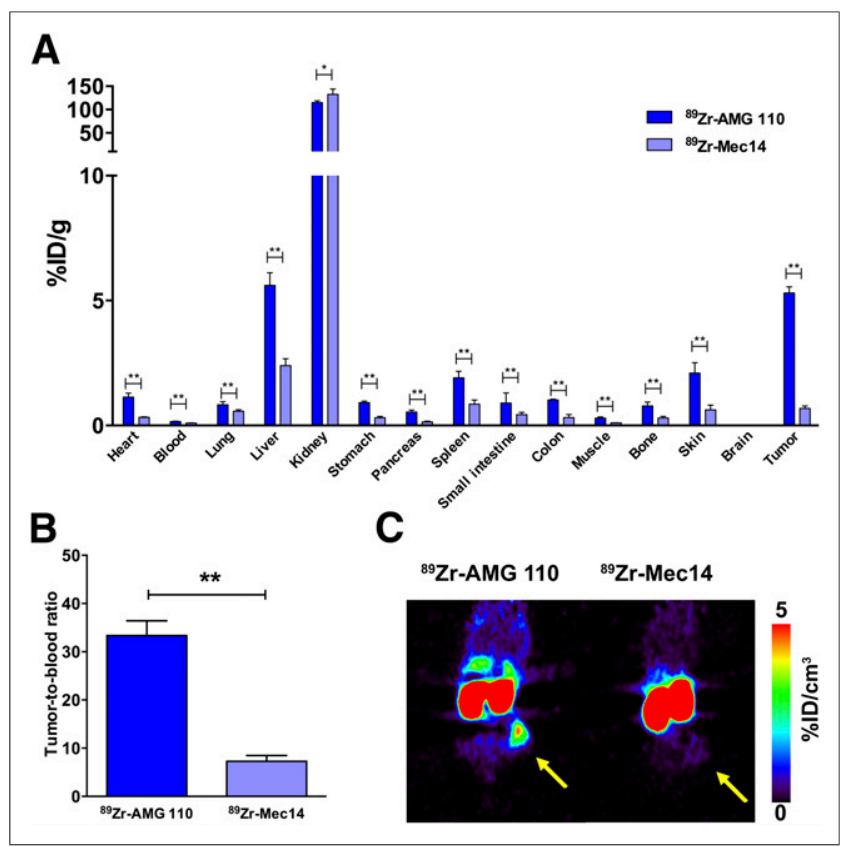

FIGURE 4. (A) Ex vivo biodistribution $24 \mathrm{~h}$ after injection of $89 \mathrm{Zr}-\mathrm{AMG}$ $110(40 \mu \mathrm{g}, n=4)$ or ${ }^{89} \mathrm{Zr}$-Mec14 $(40 \mu \mathrm{g}, n=6)$ in HT-29-tumor bearing mice. (B) Corresponding tumor-to-blood ratios were significantly higher for ${ }^{89} \mathrm{Zr}$-AMG 110 than for ${ }^{89} \mathrm{Zr}-\mathrm{Mec} 14$. (C) Representative coronal small-animal PET images of ${ }^{89} \mathrm{Zr}-\mathrm{AMG} 110$ and ${ }^{89} \mathrm{Zr}-\mathrm{Mec} 14$ visualize difference in tumor uptake. Yellow arrow indicates tumor. Data are mean $\pm \mathrm{SD} .{ }^{*} P \leq 0.05 .{ }^{*} P \leq 0.01$.
110 showed consistent tumor uptake in xenografts that is correlated with EpCAM expression. It also showed prolonged tumor retention that is unusual for a reversible extracellular binder exhibiting rapid renal clearance.

Remarkably, HT-29 tumor uptake of ${ }^{89} \mathrm{Zr}$-AMG 110 remained visible up to $72 \mathrm{~h}$ after injection, despite minimal cellular internalization. Both tumor uptake and organ uptake of ${ }^{89} \mathrm{Zr}$-AMG 110 was higher than those of ${ }^{89} \mathrm{Zr}-\mathrm{Mec} 14$, likely the result of faster clearance of ${ }^{89} \mathrm{Zr}-\mathrm{Mec} 14$, because blood levels of ${ }^{89} \mathrm{Zr}$-Mec14 were also lower. NIR fluorescent imaging with 800CW-AMG 110 confirmed AMG 110 localization at the tumor cell membrane in viable HT-29 tumor tissue. Minor accumulation of 680RD-Mec14 was observed in necrotic tumor tissue, which is likely due to nonspecific binding. Together, these findings clearly demonstrate the advantage of using immune-PET to determine the dose level of BiTE antibody constructs necessary for tumor targeting, to assess the presence of target, and to study in vivo tissue exposure in real time.

AMG 110 showed favorable tumor uptake and retention compared with a similar EpCAM binding agent. The EpCAM-targeting radiopharmaceutical ${ }^{68} \mathrm{Ga}-\mathrm{scFv}^{42}{ }_{9}$ also comprises $2 \mathrm{scFv}$ fragments and has a molecular weight $(51.2 \mathrm{kDa})$ similar to ${ }^{89} \mathrm{Zr}-\mathrm{AMG}$ 110 (15). Furthermore, it exhibits monospecific bivalent binding and higher EpCAM affinity than AMG 110 (dissociation constant $=0.24$

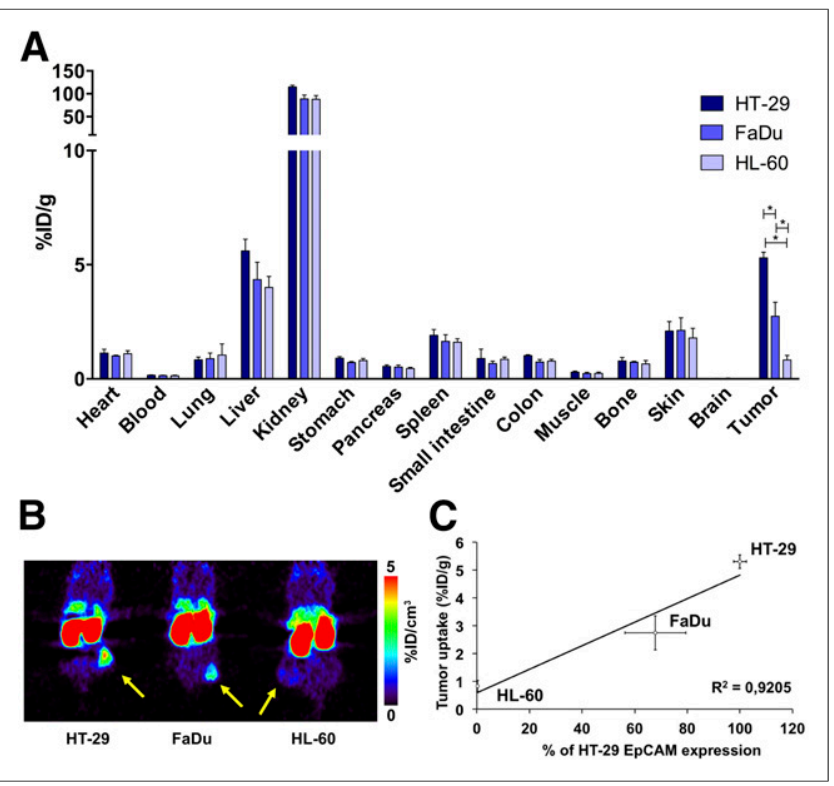

FIGURE 5. Correlation between ${ }^{89} \mathrm{Zr}$-AMG 110 tumor uptake and EpCAM expression on tumor cells. (A) Ex vivo biodistribution of ${ }^{89} \mathrm{Zr}$ AMG $110(40 \mu \mathrm{g}) 24 \mathrm{~h}$ after tracer injection in mice bearing HT-29 $(n=4$; high $\operatorname{EpCAM}), \mathrm{FaDu}(n=5$; intermediate $\mathrm{EpCAM})$, or $\mathrm{HL}-60(n=6$; EpCAM-negative) cells. (B) Representative coronal small-animal PET images. Yellow arrows indicate tumor. (C) Differences in EpCAM expression on HT-29 $(n=5)$, FaDu $(n=5)$, and HL-60 $(n=4)$ cells correlated with tumor uptake of ${ }^{89} \mathrm{Zr}$-AMG 110 . Data are mean \pm SD. ${ }^{*} P \leq 0.05$. 


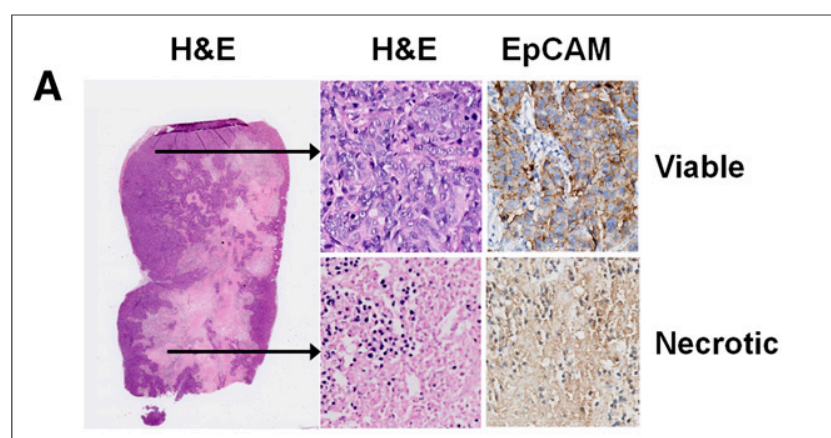

B
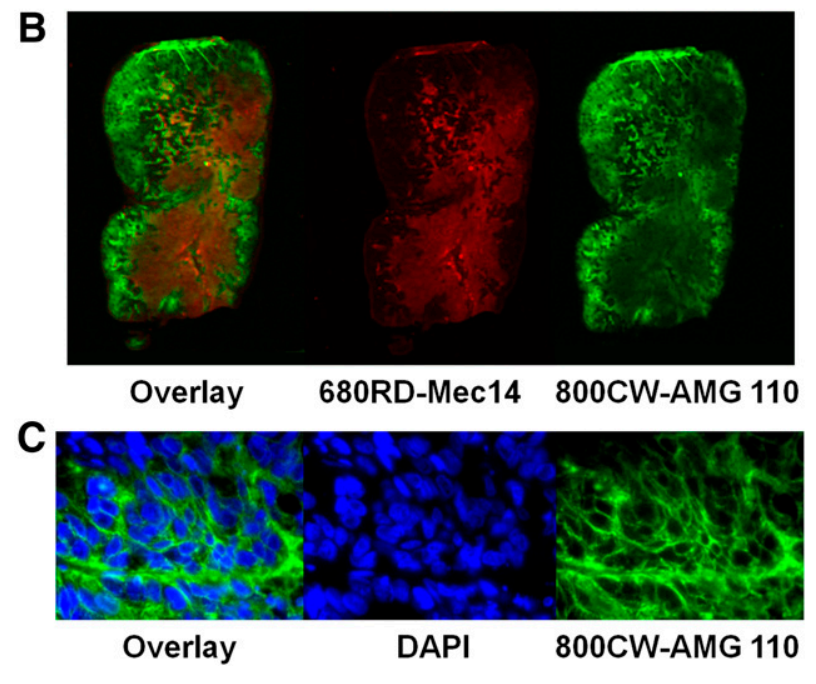

FIGURE 6. Intratumoral distribution of coinjected $800 \mathrm{CW}-\mathrm{AMG} 110$ $(40 \mu \mathrm{g})$ and 680RD-Mec14 $(40 \mu \mathrm{g})$ in HT-29 tumors. (A) EpCAM was predominantly expressed on healthy tumor tissue as visualized with hematoxylin and eosin (H\&E) and EpCAM immunohistochemical staining. (B) Corresponding macroscopic fluorescent imaging of $800 \mathrm{CW}-$ AMG 110 (green) and 680RD-Mec14 (red) distribution, with minor overlapping signal (yellow). (C) Fluorescence microscopy images (630x), visualizing membrane localization of $800 \mathrm{CW}-\mathrm{AMG} 110$ (green) and DAPI stained nuclei (blue).

vs. 170-230 nM, respectively, as determined by plasmon resonance analysis) (10). Despite bivalent binding and higher affinity, the highest tumor uptake (in $\% \mathrm{ID} / \mathrm{g}$ ) of ${ }^{68} \mathrm{Ga}-\mathrm{scFv}^{42}{ }_{9}$ in HT-29 tumors was 2.8-fold lower than ${ }^{89} \mathrm{Zr}$-AMG110 (16). Maximum tumor uptake of ${ }^{68} \mathrm{Ga}-\mathrm{scFv}^{42}{ }_{9}$ was reached at $1 \mathrm{~h}$, whereas maximum tumor uptake of ${ }^{89} \mathrm{Zr}$-AMG1 10 was reached at $6 \mathrm{~h}$ after injection. At these time points, the observed tumor-to-blood ratios were comparable $(\sim 1$ and $1.1 \pm$ 0.30 , respectively). The higher tumor uptake of ${ }^{89} \mathrm{Zr}-\mathrm{AMG} 110$ is most likely due to its longer circulating half-life $(1.4-4.1 \mathrm{~h})$ than that of ${ }^{68} \mathrm{Ga}-\mathrm{ScFv}^{42}{ }_{9}(0.97 \mathrm{~h})$.

In addition to differences in tumor uptake kinetics and circulating half-life, preclinical imaging studies also showed that different tracers also vary in the ability to saturate tumor uptake. In contrast to membrane tumor targets c-MET and human epidermal growth factor receptor 3, saturation of EpCAM binding on HT-29 was not observed even when the ${ }^{89} \mathrm{Zr}$-AMG 110 total protein dose was increased to $500 \mu \mathrm{g}(17,18)$. Thurber et al. also observed no saturation of EpCAM binding in HT-29 xenografts after injection of an EpCAM antibody labeled with a NIR dye (VivoTag 680) at a total protein dose of $180 \mu \mathrm{g}(14)$. One possible explanation might be related to the abundance of cell surface EpCAM on HT-29 cells $\left(2.3 \times 10^{6}\right.$ receptors/cell) $(14)$. Another example supporting this hypothesis was illustrated by the lack of tumor saturation observed for ${ }^{89} \mathrm{Zr}$-trastuzumab, up to $500 \mu \mathrm{g}$ in SKOV3-xenografted mice (19). Similar to the high level of EpCAM expression on HT-29 cells, expression of the human epidermal growth factor receptor 2 on SKOV3 cells is also high $\left(6.6 \times 10^{6}\right.$ receptors/cell) $(20)$. The inability to saturate human epidermal growth factor receptor 2 and EpCAM suggest that it may be difficult to saturate receptors when their cell surface expression exceeds approximately $2 \times 10^{6}$ receptors/cell at the dose levels evaluated. Alternatively, saturation of tumor targets may also depend on other in vivo properties of the antibodies including binding on/off kinetics, degree of tumor penetration, and access to targets at different protein dose levels. Additional radioactive- and opticallabeled antibody imaging studies, particularly those in the clinical setting, will help further elucidate mechanisms for driving uptake in tumors and tissues of interest.

Although the current preclinical study examined only the tumor antigen binding component of AMG 110, preclinical and clinical imaging studies showed that it is feasible to image tumor uptake of tumor-targeting CD3-bispecific antibodies in the presence of circulating T cells. A T cell-mediated increase in tumor uptake has been observed with a tetravalent bispecific tandem antibody (Tand $\mathrm{Ab}$ ), directed at mouse $\mathrm{CD} 3 \varepsilon$ and fibronectin extra domain $\mathrm{B}$, in immunocompetent mice (21). ${ }^{125}$ I-labeled TandAb with CD3 $\varepsilon$ affinity similar to that of AMG 110 showed that potential $\mathrm{T}$ cell binding outside of the tumor did not block tumor uptake or change its biodistribution (21). The mice in our study were immunodeficient, so tumor uptake of ${ }^{89} \mathrm{Zr}$-AMG 110 was not affected by $\mathrm{T}$ cells. Because AMG110 does not bind mouse CD3e, the effect of T cell binding on ${ }^{89} \mathrm{Zr}$-AMG 110 distribution and tumor uptake could not be studied in immune competent mice. In a clinical setting, the presence of $\mathrm{T}$ cells might influence biodistribution and lead to a higher tumor uptake. Furthermore, ${ }^{123} \mathrm{I}$-OC/TR F $\left(\mathrm{ab}^{\prime}\right)_{2}$, targeting folate receptor and $\mathrm{CD} 3$, has been used successfully to image malignant tumor lesions in ovarian cancer patients (22).

\section{CONCLUSION}

Given its overexpression by many tumor types, EpCAM is an interesting drug target. Different EpCAM-targeted drugs have been developed, including monoclonal antibodies, antibody fragments, bispecific antibodies, and antibody-drug conjugates. Similar to these other experimental drugs, EpCAM expression on tumor cells is a prerequisite for effective treatment with AMG 110. Because EpCAM-dependent ${ }^{89} \mathrm{Zr}$-AMG 110 tumor uptake has been demonstrated preclinically, this tracer, applied clinically, can potentially facilitate patient selection for AMG 110 treatment by providing information on drug access across all lesions. Moreover, ${ }^{89} \mathrm{Zr}$-AMG 110 or other radiolabeled BiTE antibody constructs could potentially support clinical BiTE development, because they could give additional information about tissue pharmacokinetics and uptake in tumors to support optimal dosing and about uptake in critical organs to anticipate toxicity.

\section{DISCLOSURE}

The costs of publication of this article were defrayed in part by the payment of page charges. Therefore, and solely to indicate this fact, this article is hereby marked "advertisement" in accordance with 18 USC section 1734. This work was supported by Amgen and ERC advanced grant 293445 (OnQview). Matthias Friedrich, 
Petra Deegen, Sabine K. Stienen, Pete C. Pieslor, and Hung K. Cheung are employed by Amgen and have ownership interest (including patents) in AMGEN. No other potential conflict of interest relevant to this article was reported.

\section{REFERENCES}

1. Gao J, Bernatchez C, Sharma P, Radvanyi LG, Hwu P. Advances in the development of cancer immunotherapies. Trends Immunol. 2013;34:90-98.

2. Stewart TJ, Smyth MJ. Improving cancer immunotherapy by targeting tumorinduced immune suppression. Cancer Metastasis Rev. 2011;30:125-140.

3. Garcia-Lora A, Algarra I, Garrido F. MHC class I antigens, immune surveillance, and tumor immune escape. J Cell Physiol. 2003;195:346-355.

4. Frankel SR, Baeuerle PA. Targeting T cells to tumor cells using bispecific antibodies. Curr Opin Chem Biol. 2013;17:385-392.

5. Offner S, Hofmeister R, Romaniuk A, Kufer P, Baeuerle PA. Induction of regular cytolytic T cell synapses by bispecific single-chain antibody constructs on MHC class I-negative tumor cells. Mol Immunol. 2006;43:763-771.

6. Dreier T, Baeuerle PA, Fichtner I, et al. T cell costimulus-independent and very efficacious inhibition of tumor growth in mice bearing subcutaneous or leukemic human B cell lymphoma xenografts by a CD19-/CD3- bispecific single-chain antibody construct. J Immunol. 2003;170:4397-4402.

7. Haas C, Krinner E, Brischwein K, et al. Mode of cytotoxic action of T cellengaging BiTE antibody MT110. Immunobiology. 2009;214:441-453.

8. Petsch S, Gires O, Ruttinger D, et al. Concentrations of EpCAM ectodomain as found in sera of cancer patients do not significantly impact redirected lysis and T-cell activation by EpCAM/CD3-bispecific BiTE antibody MT110. MAbs. 2011;3:31-37.

9. Went PT, Lugli A, Meier S, et al. Frequent EpCAM protein expression in human carcinomas. Hum Pathol. 2004;35:122-128.

10. Brischwein K, Schlereth B, Guller B, et al. MT110: a novel bispecific singlechain antibody construct with high efficacy in eradicating established tumors. Mol Immunol. 2006;43:1129-1143.

11. Fiedler WM, Kebenko M, Goebeler M-E, et al. A phase I study of EpCAM/CD3bispecific antibody (MT110) in patients with advanced solid tumors. J Clin Oncol. 2012;30 (suppl):2504.
12. Lamberts LE, Williams SP, Terwisscha van Scheltinga AG, et al. Antibody positron emission tomography imaging in anticancer drug development. J Clin Oncol. 2015;33:1491-1504.

13. Terwisscha van Scheltinga AG, van Dam GM, Nagengast WB, et al. Intraoperative near-infrared fluorescence tumor imaging with vascular endothelial growth factor and human epidermal growth factor receptor 2 targeting antibodies. $J$ Nucl Med. 2011;52:1778-1785.

14. Thurber GM, Weissleder R. Quantitating antibody uptake in vivo: conditional dependence on antigen expression levels. Mol Imaging Biol. 2011;13:623632.

15. Choi BD, Cai M, Bigner DD, Mehta AI, Kuan CT, Sampson JH. Bispecific antibodies engage $\mathrm{T}$ cells for antitumor immunotherapy. Expert Opin Biol Ther. 2011;11:843-853.

16. Eder M, Knackmuss S, Le Gall F, et al. ${ }^{68}$ Ga-labelled recombinant antibody variants for immuno-PET imaging of solid tumours. Eur J Nucl Med Mol Imaging. 2010;37:1397-1407.

17. Terwisscha van Scheltinga AG, Lub-de Hooge MN, Hinner MJ, et al. In vivo visualization of MET tumor expression and anticalin biodistribution with the MET-specific anticalin ${ }^{89} \mathrm{Zr}$-PRS-110 PET tracer. J Nucl Med. 2014;55: 665-671.

18. Terwisscha van Scheltinga AG, Lub-de Hooge MN, Abiraj K, et al. ImmunoPET and biodistribution with human epidermal growth factor receptor 3 targeting antibody ${ }^{89} \mathrm{Zr}-\mathrm{RG} 7116$. MAbs. 2014;6:1051-1058.

19. Dijkers EC, Kosterink JG, Rademaker AP, et al. Development and characterization of clinical-grade ${ }^{89} \mathrm{Zr}$-trastuzumab for HER2/neu immunoPET imaging. $J$ Nucl Med. 2009;50:974-981.

20. DeFazio-Eli L, Strommen K, Dao-Pick T, Parry G, Goodman L, Winslow J. Quantitative assays for the measurement of HER1-HER2 heterodimerization and phosphorylation in cell lines and breast tumors: applications for diagnostics and targeted drug mechanism of action. Breast Cancer Res. 2011;13: R44.

21. List T, Neri D. Biodistribution studies with tumor-targeting bispecific antibodies reveal selective accumulation at the tumor site. MAbs. 2012;4:775-783.

22. Tibben JG, Boerman OC, Massuger LF, Schijf CP, Claessens RA, Corstens FH. Pharmacokinetics, biodistribution and biological effects of intravenously administered bispecific monoclonal antibody OC/TR $\mathrm{F}\left(\mathrm{ab}^{\prime}\right)_{2}$ in ovarian carcinoma patients. Int J Cancer. 1996;66:477-483. 